\title{
Nomogram prediction of surgical site infection of HIV-infected patients following orthopedic surgery: a retrospective study
}

\author{
Rui Ma, Jie He, Biao Xu, Changsong Zhao, Yao Zhang, Xin Li, Sheng Sun and Qiang Zhang*
}

\begin{abstract}
Background: Surgical site infection (SSI) is a devastating complication of orthopedic surgery, related with increased morbidity and mortality. This study was performed with the aim to compare the SSI rate in human immunodeficiency virus HIV-positive patients, to identify other risk factors for SSI and to establish a nomogram model to predict the risk of SSI.

Methods: A total of 101 HIV-positive individuals following orthopedic surgery patients admitted to Beijing Ditan Hospital. Their characteristics were gathered. The univariate and multiple logistic regression analysis were performed to explore the risk factors of SSI. And the Nomogram prediction model was constructed and verified.

Results: The independent predictive factors of SSI included CD4 (Odds ratio [OR], 0.041; $P=0.040$ ), erythrocyte sedimentation rate $(E S R)(O R, 89.773 ; P=0.030)$, and procalcitonin $(P C T)(O R, 220.746 ; P=0.006)$. The scoring nomogram model was as follows: Logit $\left.(S S I)=-2.63589-0.00314^{*} C D 4<430.75=1\right)+0.04695^{*}(E S R<17.46=1)+$ $2.93694^{*}(\mathrm{PCT}<0.22=1)$. The area under the Receiver Operating Characteristic $(\mathrm{ROC})$ curve was 0.946 . The cutoff score was -2.1026 with a sensitivity of $93.33 \%$ and a specificity of $84.88 \%$.
\end{abstract}

Conclusions: CD4, ESR, PCT might affect the occurrence of SSI after orthopedic surgery. The nomogram model constructed in this study is helpful for predicting the probability of SSI.

Keywords: Nomogram, Surgical site infection, Orthopedic, HIV, CD4, Erythrocyte sedimentation rate

\section{Introduction}

Surgical site infection (SSI) is an adverse complication of orthopedic surgery and can increase the risk of readmission [1, 2]. Moreover, SSI often caused poor prognosis, decreased quality of life and the possibility of reoperation [3, 4]. It is well known that HIV patients are more likely to develop SSI than those who are not infected with HIV due to their dramatically decreased CD4 cell count and weak immune resistance [5]. With the extension of HIV infection time, the probability of opportunistic infection

\footnotetext{
*Correspondence: m17610821776@163.com
}

Department of Orthopaedics, Beijing Ditan Hospital, Capital Medical University, No. 8 Jingshun East Street, Chaoyang District, Beijing 100015, China

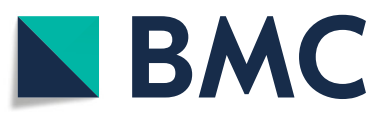

increases greatly, and postoperative orthopedic incision is prone to infection [6].

In clinical orthopedic surgery, internal fixation and implant devices are often used. Due to the body's autoimmunity rejection of foreign objects, the chance of postoperative wound infection is greatly increased [7]. Internal fixation and implant devices are kept in the body for a long time, creating space and attachments for the growth of pathogens. Therefore, not only does the incidence of SSI increase in the early stage of orthopedic surgery, but it also increases the risk of infection in the later stage. If the internal fixation and implant devices become infected, the body must be treated with antibiotics for a long time, and the internal fixation and

(c) The Author(s). 2020 Open Access This article is licensed under a Creative Commons Attribution 4.0 International License, which permits use, sharing, adaptation, distribution and reproduction in any medium or format, as long as you give appropriate credit to the original author(s) and the source, provide a link to the Creative Commons licence, and indicate if changes were made. The images or other third party material in this article are included in the article's Creative Commons licence, unless indicated otherwise in a credit line to the material. If material is not included in the article's Creative Commons licence and your intended use is not permitted by statutory regulation or exceeds the permitted use, you will need to obtain permission directly from the copyright holder. To view a copy of this licence, visit http://creativecommons.org/licenses/by/4.0/ The Creative Commons Public Domain Dedication waiver (http://creativecommons.org/publicdomain/zero/1.0/) applies to the data made available in this article, unless otherwise stated in a credit line to the data. 
implant devices should be removed or replaced as soon as possible. This will greatly increase the medical costs of patients [8]. Currently, there are few quantitative studies and prediction models which show that HIV virus and reduced $\mathrm{CD} 4$ count increase the risk of infection with internal fixation and implant devices during orthopedic surgery $[9,10]$. According to WHO guidelines on infection prevention and control, penicillin should be used for prevention as soon as 1 hour after orthopedic surgery, and the duration should not exceed 24. $\mathrm{h}$ [11]. However, clinicians generally expect the incidence of postoperative SSI to be less than 2\% [12].

Although there are currently surgical guidelines for internal fixation and implant devices, these are based only on data from non-HIV patients. Specific orthopedic guidelines for HIV patients do not yet exist. Therefore, it is necessary for orthopedic surgeons in hospitals with infectious diseases to formulate corresponding operational guidelines. The purpose of this study was to develop a Nomogram prediction model for the incidence of SSI in patients with HIV who underwent orthopedic internal fixation and implant surgery.

\section{Materials and methods}

\section{Patients and ethics}

This study is a retrospective study. A total of 101 patients with HIV-positive fractures were enrolled in our department. We have referred to this document and calculated the sample size required for this study [13]. The results are as follows. Therefore, $101 \mathrm{HIV}$-positive patients can satisfy this study. Follow up by phone and notify the patient of the infection. Observe whether the wound is infected according to the guidelines for infection at the surgical site. The follow-up time was 1 year. The follow-up rate in this study was $100 \%$. These patients underwent orthopedic surgery between April 2018 and August 2019 in the Beijing Ditan Hospital. Antibiotic dosage is $8 \mathrm{~g} /$ day cefradine. The surgeries were performed by professors in our orthopedic department and all surgeons have performed orthopedic surgery for more than 500 cases. Patients with open fractures require emergency surgery and contaminated wounds were excluded. Patients with poor liver and kidney function were excluded for the high risk of postoperative complications and death (Fig. 1). Laboratory examination of abnormal liver function is mainly manifested as AST and/or ALT $>40 \mathrm{U} / \mathrm{L}$. The criterion of abnormal kidney function is mainly manifested as creatinine $>115 \mathrm{umol} / \mathrm{L}$ (male) or $>97 \mathrm{umol} / \mathrm{L}($ female), urea nitrogen $>7.1 \mathrm{umol} / \mathrm{L}$.

Preoperative treatment including intravenous or oral amino acids, albumin injection, and thymopentin were administered as routine nutritional supplementation to improve nutrition and hypoalbuminemia. Infusions of

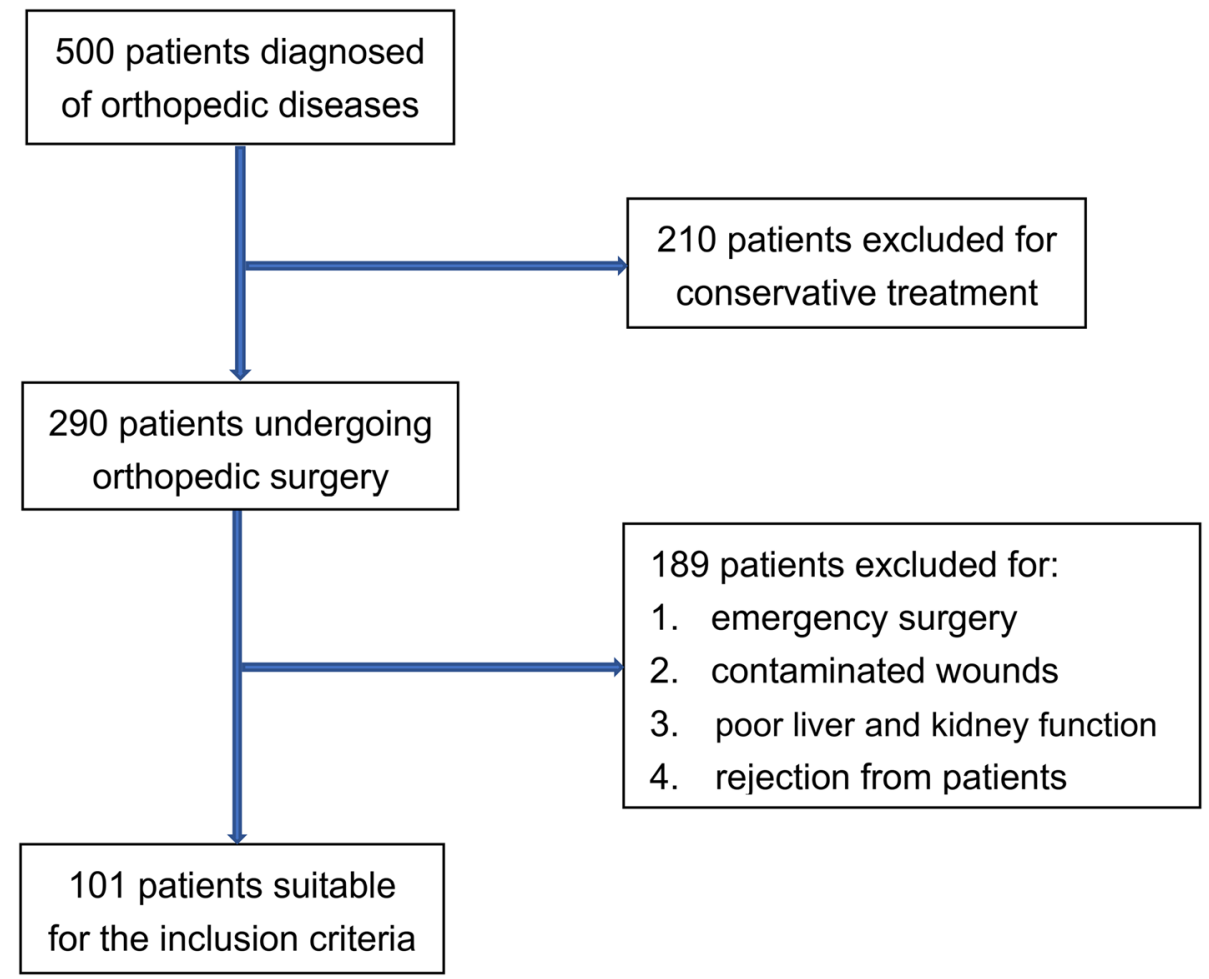

Fig. 1 Selection process for patients suitable for the inclusion criteria 
red blood cell suspension and/or plasma were administered as necessary. A second-generation cephalosporin was routinely administered within $2 \mathrm{~h}$ of the skin incision for all patients. In patients with allergies to cephalosporins, clindamycin was an acceptable alternative. Antibiotics were administered for 3 days and then continued as needed based on the incision condition, body temperature, white blood cell count, erythrocyte sedimentation rate, $\mathrm{C}$-reactive protein level, and bacterial culture. Low molecular weight heparin and venous pressure pump were utilized postoperatively to prevent DVT(Deep venous thrombosis)s [14].

This study was approved by the Ethical Committee of the Beijing Ditan Hospital. And the written informed consent was obtained from the all patients.

\section{The diagnosis of SSI}

The diagnosis of SSI was confirmed by postoperative incision observation and imaging examination. All participants underwent clean implant orthopaedic surgery and the incidence of SSI was evaluated. The classification of SSI was based on Systematic Literature Review on the Management of Surgical Site Infections (June 2018) published by the American Academy of Orthopaedic Surgeons (AAOS) [15]. The SSI criteria used were those established by the Centers for disease control and prevention guideline for the prevention of surgical site infection [16].

\section{The clinical variables}

We collect clinical data through patient medical records and follow-up. All the laboratory results were baseline data. Select variables known to be associated with SSI were chosen for inclusion in the nomogram including sex, age, basic disease [17] (that is hypertension, diabetes, coronary heart disease, and so on), surgical methods (open or minimally surgical technique), operation time, CD4 of peripheral blood, HIVRNA, creatinine, albumin, C-reactive protein (CRP), Globulin, ESR (Erythrocyte sedimentation rate), PCT(Procalcitonin), Ddimmer. In this study, the mean value was used as the critical value. All laboratory tests are performed the day before surgery.

The basic disease refers to the long-term/chronic coexisting disease that affects basic metabolism, immune function, and vital organs that the patient itself has. The basic diseases mainly include the following three types of diseases: basic metabolic disorders, low immune function and major chronic wasting diseases.

\section{Statistics}

SPSS 25.0 (IBM Corp., Armonk, NY, USA) statistical software was used to analyze the data. Quantitative variables were shown as the mean \pm standard deviation (SD).
Qualitative variables were described by absolute frequencies and percentages. The descriptive statistical method of mean $\pm \mathrm{SD}$ is adopted in the measurement data, and the frequency and percentage description method are used in the counting data.

For continuous variables, the rank sum test of Kruskal Wallis was used. For counting variables with theoretical number $<10$, the Fisher exact probability test was used. Risk factors were screened by univariate and multiple logistics regression. Perioperative clinical characteristics associated with postoperative (incisional and organ/ space) SSI were analyzed by univariate analyses.

\section{Construction of the nomogram prediction model}

The nomogram was established with $\mathrm{R}$ (http://www.Rproject.org) and Empower Stats (X\&Y Solutions Inc., Boston, MA, USA) software. In the single and multiple logistic regression model, indicators with $\mathrm{P}$ less than 0.05 are included in the nomogram model. Based on the total score obtained from the analysis results, the reliability of the risk assessment model based on the total score was evaluated by ROC analysis method, and a post-operation SSI risks assessment model was established.

\section{Results}

\section{Associations between characteristics and SSI}

The incidence of SSI in this research was $14.85 \%$. Table 1 summarized the associations between potentially risk factors and the SSI according to the rank sum test of Kruskal Wallis and the Fisher exact probability test. Among the individuals, the basic disease $(P=0.020)$, operation time $(P=0.005)$ and CD4 $(P=0.044), \operatorname{CRP}(P=0.003), \operatorname{ESR}(P<$ $0.001)$, PCT $(P<0.001)$, D-dimmer $(P<0.001)$ were markedly related to the SSI (Table 1). The incidence of SSI in the patients with high HIVRNA expression was $17.39 \%$, which is higher than the patients with low HIVRNA expression $(14.10 \%)(P>0.05)$ (Table 1$)$.

\section{The risk factors of SSI based on univariate logistic regression analysis}

Table 2 presents the univariate OR and 95\% confidence intervals $(95 \% \mathrm{CI})$ for SSI. The OR for SSI was 0.121 (95\% CI, $0.015-0.960, P=0.046)$ in the group without basic disease compared with patients with basic disease. For SSI, long operation time had higher OR of 9.783 (95\% CI, 1.977-48.412, $P=0.005$ ) than subjects with $1-2 \mathrm{~h}$ ' operation time. Subjects who had high CD4, had obviously lower incidence of SSI than subjects who had low CD4, and the OR is 0.239 (95\% CI, 0.063-0.906, $P=0.035$ ). Moreover, the higher risk of SSI was often accompanied by the higher levels of CRP (OR, 7.714; $P=0.001$ ), ESR (OR, 11.636; $P=$ $0.000)$, PCT (OR, 44.550; $P=0.000)$, D-dimmer (OR, 4.913; $P=0.008$ ) (Table 2). 
Table 1 The association between clinical and pathological characteristics and SSI

\begin{tabular}{|c|c|c|c|}
\hline \multirow[t]{2}{*}{ Characteristics } & \multicolumn{2}{|l|}{ SSI } & \multirow[t]{2}{*}{$P$-value } \\
\hline & No $(n=86)$ & Yes $(n=15)$ & \\
\hline Sex & & & 0.463 \\
\hline Male & 83 (96.5\%) & 15 (100.0\%) & \\
\hline Female & $3(3.5 \%)$ & $0(0.0 \%)$ & \\
\hline Age & $42.9 \pm 14.1$ & $39.7 \pm 12.5$ & 0.406 \\
\hline Basic disease & & & $0.020^{*}$ \\
\hline Yes & $54(62.8 \%)$ & $14(93.3 \%)$ & \\
\hline No & 32 (37.2\%) & $1(6.7 \%)$ & \\
\hline Surgical methods & & & 0.107 \\
\hline Microsurgery & 64 (74.4\%) & $14(93.3 \%)$ & \\
\hline Open surgery & $22(25.6 \%)$ & $1(6.7 \%)$ & \\
\hline Operation time & & & $0.005^{*}$ \\
\hline $1-2 \mathrm{~h}$ & 45 (52.3\%) & $2(13.3 \%)$ & \\
\hline $2-3 h$ & 18 (20.9\%) & $3(20.0 \%)$ & \\
\hline$\geq 3 \mathrm{~h}$ & $23(26.7 \%)$ & $10(66.7 \%)$ & \\
\hline CD4 & $449.2 \pm 229.3$ & $324.9 \pm 132.4$ & $0.044^{*}$ \\
\hline HIVRNA & & & 0.697 \\
\hline Low & 67 (77.9\%) & $11(73.3 \%)$ & \\
\hline High & 19 (22.1\%) & $4(26.7 \%)$ & \\
\hline Creatinine & $70.9 \pm 14.3$ & $64.4 \pm 12.0$ & 0.103 \\
\hline CRP & $9.7 \pm 19.9$ & $27.6 \pm 26.2$ & $0.003^{*}$ \\
\hline Albumin & $44.5 \pm 7.0$ & $42.3 \pm 5.1$ & 0.245 \\
\hline Globulin & $28.9 \pm 4.5$ & $31.6 \pm 6.2$ & $0.047^{*}$ \\
\hline ESR & $14.5 \pm 15.4$ & $34.2 \pm 21.1$ & $<0.001^{*}$ \\
\hline PCT & $0.1 \pm 0.2$ & $0.9 \pm 0.7$ & $<0.001^{*}$ \\
\hline D-dimmer & $1.7 \pm 3.0$ & $7.1 \pm 10.3$ & $<0.001^{*}$ \\
\hline
\end{tabular}

\section{The independent risk factors for SSI based on} multivariate logistic regression

In order to effectively control the influence of confounding factors, all risk factors were incorporated into the multivariate logistic regression model simultaneously, which can also predict the most independent risk characteristic. Multivariate logistic regression analysis showed that risk factors indicating overall postoperative SSI included CD $4<430.75 /$ ul(OR[CD4 > 430.75/ul VS. CD $4<430.75 / \mathrm{ul}]: 0.041 ; 95 \%$ CI:0.0020.868; $\quad P<0.040), \quad$ ESR $>17.46($ OR $[$ ESR $>17.46 \quad$ VS ESR $<17.46]$ : $89.773 ; 95 \%$ CI: $1.551-5195.833 ; \quad P=$ $0.030), \quad \mathrm{PCT}>0.22(\mathrm{OR}[\mathrm{PCT}>0.22$ VS $\mathrm{PCT}<0.22]$ : 220.746; $95 \% \quad$ CI: $4.829-10,091.115 ; \quad P=0.006)$ (Table 3).
Table 2 Correlative parameters' effect on SSI based on univariate logistic regression analysis

\begin{tabular}{|c|c|c|c|c|c|}
\hline \multicolumn{3}{|l|}{ Characteristics } & \multicolumn{3}{|l|}{ SSI } \\
\hline & & & $\overline{\mathrm{OR}}$ & $95 \% \mathrm{Cl}$ & $\mathbf{P}$ \\
\hline \multirow[t]{2}{*}{ Sex } & Male & 98 & 1 & & 0.999 \\
\hline & Female & 3 & 0.000 & $0.000-0.000$ & \\
\hline \multirow[t]{2}{*}{ Age } & $\leq 65$ & 91 & 1 & & 0.652 \\
\hline & $>65$ & 10 & 0.611 & $0.072-5.210$ & \\
\hline \multirow[t]{2}{*}{ Basic disease } & Yes & 68 & 1 & & $0.046^{*}$ \\
\hline & No & 33 & 0.121 & $0.015-0.960$ & \\
\hline \multirow[t]{2}{*}{ Surgical methods } & Microsurgery & 78 & 1 & & 0.140 \\
\hline & Open surgery & 23 & 0.208 & $0.026-1.673$ & \\
\hline \multirow[t]{3}{*}{ Operation time } & $1-2 \mathrm{~h}$ & 47 & 1 & & \\
\hline & $2-3 h$ & 21 & 3.750 & $0.577-24.351$ & 0.166 \\
\hline & $\geq 3 \mathrm{~h}$ & 33 & 9.783 & $1.977-48.412$ & $0.005^{*}$ \\
\hline \multirow[t]{2}{*}{ CD4 } & Low & 54 & 1 & & $0.035^{*}$ \\
\hline & High & 47 & 0.239 & $0.063-0.906$ & \\
\hline \multirow[t]{2}{*}{ HIVRNA } & Low & 78 & 1 & & 0.296 \\
\hline & High & 23 & 1.889 & $0.573-6.225$ & \\
\hline \multirow[t]{2}{*}{ Creatinine } & Low & 54 & 1 & & 0.583 \\
\hline & High & 47 & 0.732 & $0.240-2.234$ & \\
\hline \multirow[t]{2}{*}{ CRP } & Low & 78 & 1 & & $0.001^{*}$ \\
\hline & High & 23 & 7.714 & $2.368-25.131$ & \\
\hline \multirow[t]{2}{*}{ Albumin } & Low & 56 & 1 & & 0.347 \\
\hline & High & 45 & 0.575 & $0.181-1.823$ & \\
\hline \multirow[t]{2}{*}{ Globulin } & Low & 52 & 1 & & 0.339 \\
\hline & High & 49 & 1.725 & $0.565-5.269$ & \\
\hline \multirow[t]{2}{*}{ ESR } & Low & 67 & 1 & & $0.000^{*}$ \\
\hline & High & 34 & 11.636 & $3.002-45.098$ & \\
\hline \multirow[t]{2}{*}{ PCT } & Low & 85 & 1 & & $0.000^{*}$ \\
\hline & High & 16 & 44.550 & 10.368-191.417 & \\
\hline \multirow[t]{2}{*}{ D-dimmer } & Low & 81 & 1 & & $0.008^{*}$ \\
\hline & High & 20 & 4.913 & $1.520-15.887$ & \\
\hline
\end{tabular}

OR odds ratio, $95 \% \mathrm{Cl} 95 \%$ confidence interval. ${ }^{*} P<0.05$

\section{The nomogram and its predictive performance}

The regression co-effificients from logistic model were used to construct the model for estimation of SSI risk. The standardized net benefit, high risk threshold, and benefit ratio of model were manifested (Fig. 2). The scoring model was as follows: Logit $(\mathrm{SSI})=-2.63589-$ $0.00314 * \mathrm{CD} 4<430.75 / \mathrm{ul}=1)+0.04695 *(\mathrm{ESR}<17.46=$ $1)+2.93694^{*}(\mathrm{PCT}<0.22=1)$, which was also presented visually (Fig. 3).

The verification of sensitivity and specificity of nomogram model

The performance of the nomogram was measured by ROC curves and the area under curve (AUC) was 0.946 
Table 3 Correlative genes' effect on SSI based on multiple logistic regression analysis

\begin{tabular}{llll}
\hline Characteristics & SSI & & \\
\cline { 2 - 4 } & OR & $\mathbf{9 5 \% ~ C l}$ & $\mathbf{P}$ \\
\hline Sex & 0.000 & $0.000-0.000$ & 0.999 \\
Age & 0.018 & $0.000-1.619$ & 0.080 \\
Basic disease & 0.044 & $0.000-5.403$ & 0.203 \\
Surgical methods & 0.267 & $0.008-8.516$ & 0.455 \\
Operation time & 1.141 & $0.245-5.313$ & 0.867 \\
CD4 & 0.041 & $0.002-0.868$ & $0.040^{*}$ \\
HIVRNA & 0.085 & $0.003-2.256$ & 0.140 \\
Creatinine & 30.768 & $0.744-1272.930$ & 0.071 \\
CRP & 2.278 & $0.116-44.604$ & 0.588 \\
Albumin & 1.269 & $0.088-18.394$ & 0.862 \\
Globulin & 0.456 & $0.039-5.317$ & 0.531 \\
ESR & 89.773 & $1.551-5195.833$ & $0.030^{*}$ \\
PCT & 220.746 & $4.829-10,091.115$ & $0.006^{*}$ \\
D-dimmer & 11.780 & $0.204-679.695$ & 0.233 \\
\hline OR
\end{tabular}

OR odds ratio, $95 \% \mathrm{Cl} 95 \%$ confidence interval. ${ }^{*} P<0.05$
(95\% CI 0.901-0.991) in the model from observed data. The cut-off score was -2.1026 with a sensitivity of $93.33 \%$ and a specificity of $84.88 \%$ (Fig. 4).

\section{Discussion}

In this study, we sought to identify the independent risk factors in adult patients susceptible to SSI after instrumented fusion surgery for orthopedic diseases. We analyzed the clinical data of 101 patients who underwent orthopedic surgery in Beijing Ditan Hospital from April 20 to August 2019. According to whether patients had SSI, they were divided into two groups. Preoperative $\mathrm{CD} 4 \mathrm{~T}$ cells, presence or absence of opportunistic infection, and organ dysfunction were used to identify whether there was SSI in the patients [16].

According to the results, SSI is mainly related to factors such as basic disease, operation time and CD4, CRP, ESR, $\mathrm{PCT}$, and D-dimmer. Multivariate logistic regression analysis showed that risk factors indicating overall postoperative SSI included CD $4<430.75 / \mathrm{ul}$, ESR $>17.46$, and PCT $>0.22$. The scoring model was as follows:Logit(SSI $)=$ $-2.63589-0.00314 * \mathrm{CD} 4<430.75 / \mathrm{ul}=1)+0.04695 *(\mathrm{ESR}<$ $17.46=1)+2.93694 *(\mathrm{PCT}<0.22=1)$. The model consisting of risk factors might be used to accurately assess whether a patient has SSI.

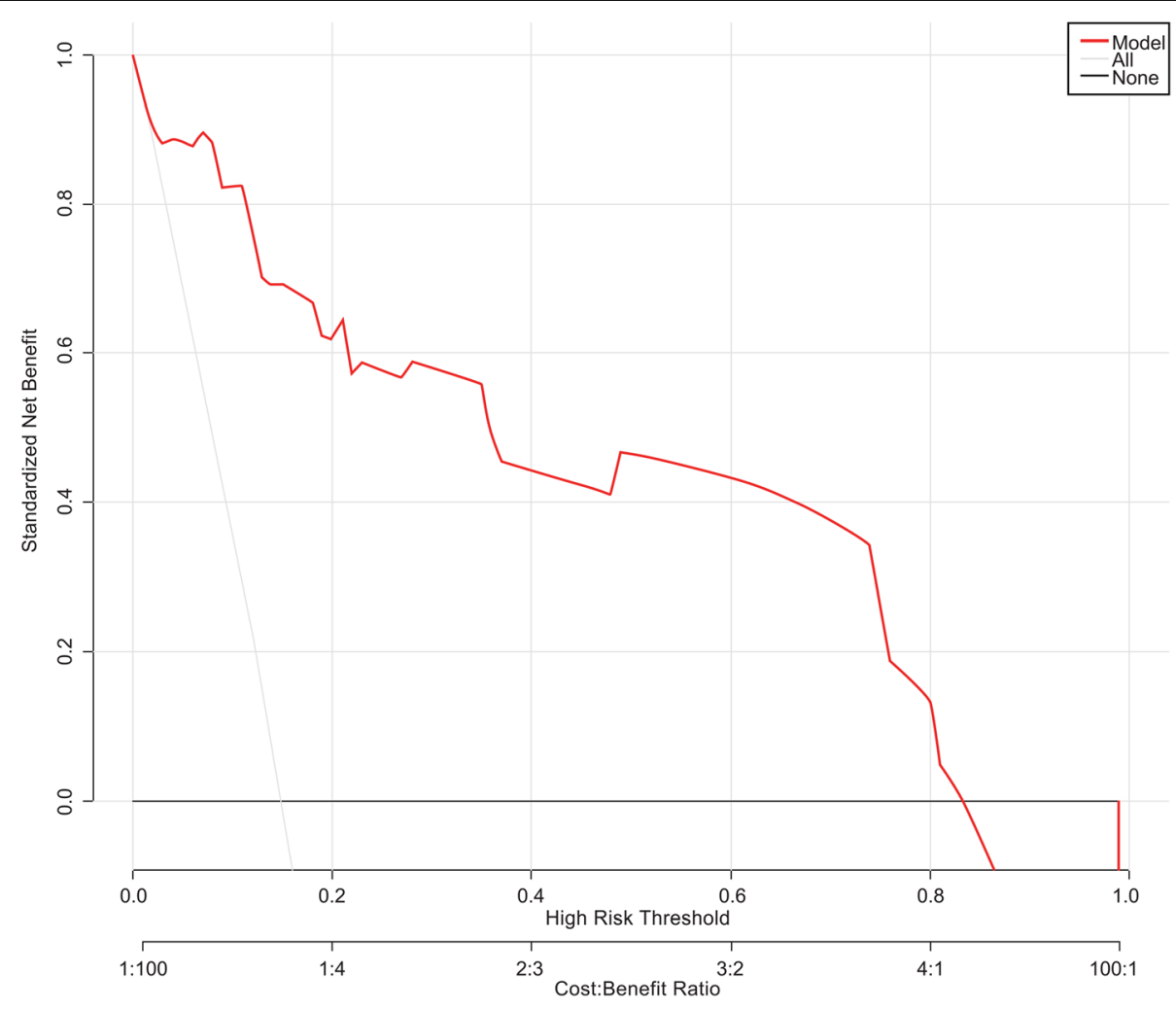

Fig. 2 The standardized net benefit, high risk threshold, and benefit ratio of model 


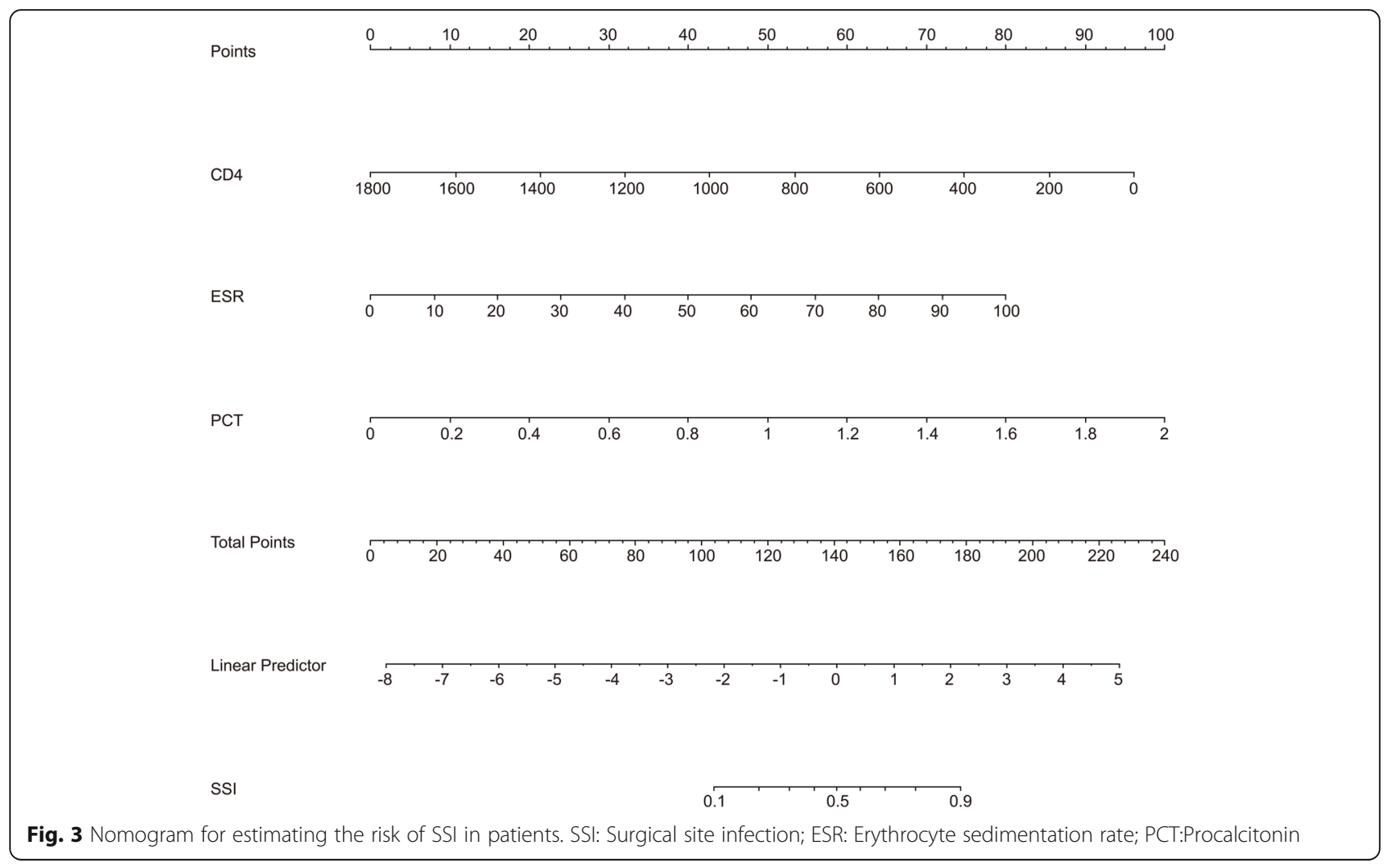

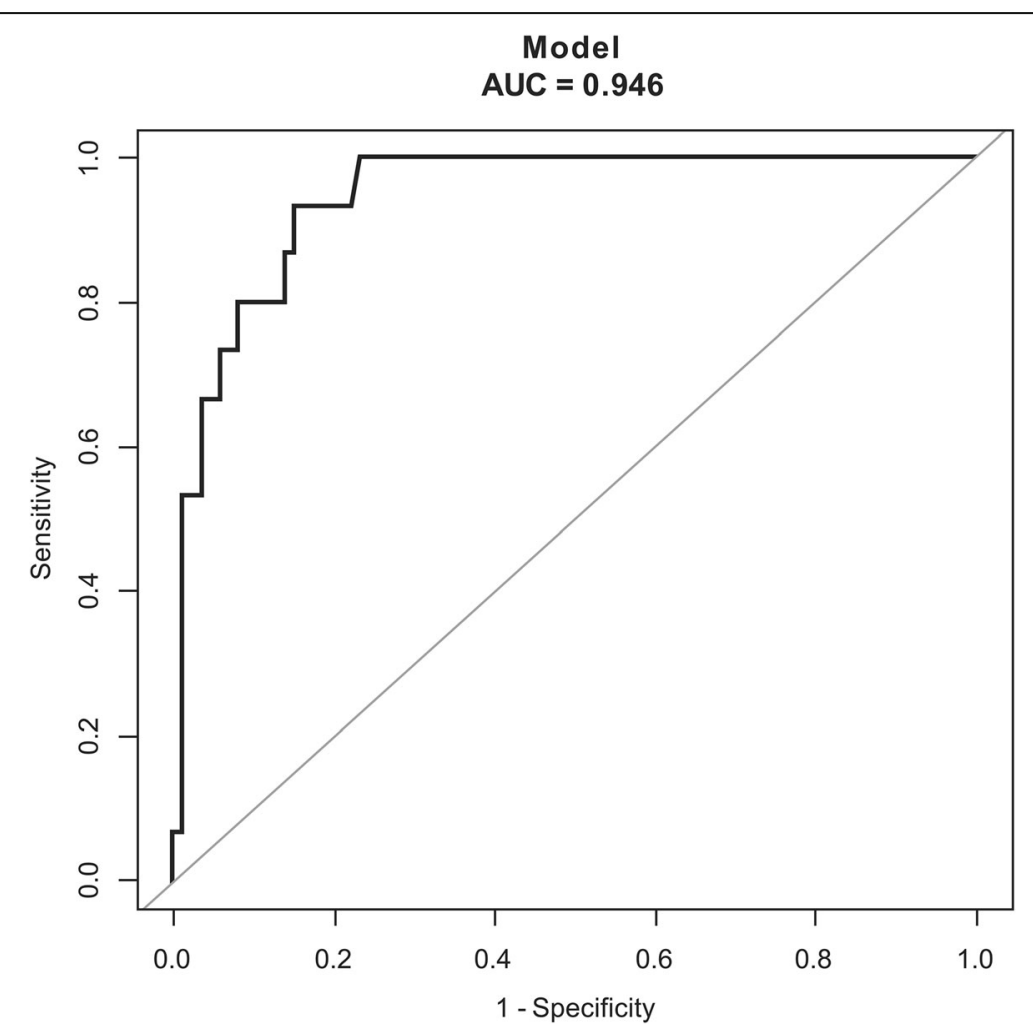

Fig. 4 The ROC of the model from observed data (nomogram) was 0.946 . The cutoff score was -2.1026 with a sensitivity of $93.33 \%$ and a specificity of $84.88 \%$. ROC: Receiver Operating Characteristic; AUC: Area under curve 
The results of this study were slightly different from the results reported in the current literature. Firstly, the subjects in the former study [18] were all a type of incision, but the results of this study did not include the relevant factors of the incision category. Moreover, targeted application of nutritional support treatment before surgery, so that patients better tolerate surgery, so albumin and hemoglobin have not become a risk factor affecting surgical site infection [19]. Pay attention to perioperative nutritional support and immune reconstitution in HIV-positive patients, correct treatment of hypoproteinemia and anemia, and infusion of plasma or suspended red blood cells if necessary [19]. Older patients should be paid more attention to the adjustment of this situation. The results of this study showed that the SSI rate was $14.85 \%$, further confirming the significance of standardized treatment during perioperative period.

The CD4+ T count were significantly associated with the incidence of SSI in patients [20]. Reported in the literature, CD4 T lymphocyte count $<200 / \mathrm{ul}$ and viral load $>500,000$ copies/ul, the incidence of postoperative incision infection wound would increase [21]. Therefore, in order to prevent surgical site infection, it is necessary to control the patient's CD4 count and improve the patient's immunity status [22]. At the same time, apply clinical classification of HIV System, to assess the safety of surgery, for patients with CD4 $\mathrm{T}$ lymphocyte count higher than grade 2, careful consideration of surgery, it is best to adjust the CD4 $\mathrm{T}$ lymphocyte count to a higher level after elective surgery, it is best to improve the perioperative adjuvant treatment after elective surgery [23].

However, the choice of whether to operate and the timing of surgery cannot be completely dependent on the CD4 T count, and it is necessary to determine the tolerance to surgery in combination with the patient's general condition, such as ESR and PCT.

The ESR level also affected the incidence of surgical site infections in orthopedic patients with HIVpositive patients. HIV patients have low or even reduced immunity and a higher risk of opportunistic infections [24]. More and more complex internal fixations were likely to cause infection of the incision, and the disturbance to the physiological function of the body is also large, which could active the inflammatory system [25]. When the acute inflammation occurred, blood acutephase reactant increased rapidly, including $\alpha$-antirypsin, $\alpha 2$-mactoglobulin, $C$ reactive protein, haptoglobin, transferrin, fibrinogen, etc. [26]. The main reason is that the above components, which were released increasingly, could promote the rouleylike aggregation of red blood cells to a greater or lesser extent [27]. The rapid increase of ESR could be seen in 2-3 days after the occurrence of inflammation. Therefore, under the premise of following the basic principles of orthopedic surgery, surgery should use precise incision, fixation tendencies, such as the selection of simple and effective fixed equipment. The ESR level should be detected timely to estimate the incidence of SSI.

PCT is a protein, which increased in the SSI patients $(\mathrm{OR}=220.746, P<0.05)$. Its levels in the plasma rose in severe bacterial, fungal and parasitic infections as well as sepsis [28]. Bacterial endotoxin played an important role in the induction process [29]. PCT was a parameter for the diagnosis and monitoring of bacterial inflammatory disease infections. Elevated PCT levels occurred in severe shock, systemic inflammatory response syndrome and multiple organ dysfunction syndrome [29]. PCT was closely related to the occurrence and process of severe bacterial and septicemic infections, and could accurately reflect whether the source of infection causing lesions (such as peritonitis) has been eradicated [30]. Daily monitoring of PCT concentrations provided a reliable evaluation of treatment outcomes. PCT might be used to monitor surgical trauma or compound trauma.

The nomogram could be used to predict the risk of HIV positive patients and decided whether to undergo surgical treatment and preoperative interventions. The nomogram model helped doctors in treatment decisions. Compared with traditional tools (such as the NHSN index), the nomogram established in this study was more suitable for the assessment of infection risk of HIV positive patients after orthopedic surgery. Limited by the nature of the sample, this study was suitable for risk assessment of HIV positive patients after orthopedic surgery. In follow-up studies, we would include more samples and extend it to other populations.

However, there were some defects in the research. No a priori threshold was pre-specified, this might lead to a bias in the interpretation of the tests and generalisability of the results. Due to the nature of the sample, this study had certain limitations. In follow-up research, we would add some of the most common descriptive information to enhance the generality of the results. In a short period of time, no more samples could be collected, so in follow-up research, we would conduct external verification of the nomogram. The optimal cut-off point was calculated by Youden's index method. And we would conduct external verification and include more indicators in follow-up research.

\section{Conclusion}

In summary, a combination of CD4, ESR, and PCT might help researchers predict the incidence of SSI. Furthermore, the risk factors of SSI after clean implant orthopedic surgery in patients might provide the better evidence to guide the diagnosis and treatment of post- 
surgery SSI. The nomogram can be used to predict the risk of AIDS patients and decide whether to undergo surgical treatment and preoperative interventions. The nomogram model helps doctors in treatment decisions.

\section{Abbreviations}

SSI: Surgical site infection; OR: Odds ratio; ROC: Receiver Operating Characteristic; ESR: Erythrocyte sedimentation rate; PCT: Procalcitonin; AAOS: American Academy of Orthopaedic Surgeons; CRP: C-reactive protein; SD: Standard deviation; AUC: Area under curve

\section{Acknowledgements}

Not applicable.

\section{Authors' contributions}

RM and QZ conceptualized the study. JH, BX and CSZ were responsible for data curation, formal analysis and wrote the original draft. YZ, XL and SS were responsible for resources, supervision, validation and visualization. All authors read and approved the final manuscript.

\section{Funding}

The research was supported by Capital's Funds for Health Improvement and Research (No. 2018-2-2174), Beijing Municipal Science \& Technology Commission (No. Z191100006619060), and Scientific Research Common Program of Beijing Municipal Commission of Education, (No. KM201810025029).

\section{Availability of data and materials}

The datasets used and analysed during the current study are available from the corresponding author on reasonable request.

\section{Ethics approval and consent to participate}

All procedures were in accordance with the ethical standards of the Ethical Committee of the Beijing Ditan Hospital (2017-029) and with the 1964 Helsinki declaration and its later amendments. All applicable international, national, and/or institutional guidelines for the care and use of human were followed. The written informed consent was obtained from the all patients.

\section{Consent for publication}

Not applicable.

\section{Competing interests}

The authors declare that they have no competing interests.

Received: 7 March 2020 Accepted: 11 November 2020

Published online: 26 November 2020

\section{References}

1. Wang $\mathrm{H}$, Pei $\mathrm{H}$, Chen $\mathrm{M}$, Wang $\mathrm{H}$. Incidence and predictors of surgical site infection after ORIF in calcaneus fractures, a retrospective cohort study. J Orthop Surg Res. 2018;13(1):293.

2. de Vries FE, Gans SL, Solomkin JS, et al. Meta-analysis of lower perioperative blood glucose target levels for reduction of surgical-site infection. Br I Surg. 2017;104(2):e95-e105.

3. Deery SE, Cavallaro PM, McWalters ST, et al. Colorectal Surgical Site Infection Prevention Kits Prior to Elective Colectomy Improve Outcomes. Ann Surg. 2019:271(6):1110-15.

4. Mazmudar A, Castle J, Yang AD, Bentrem DJ. The association of length of hospital stay with readmission after elective pancreatic resection. J Surg Oncol. 2018;118(1):7-14.

5. Guild GN, Moore TJ, Barnes W, Hermann C. CD4 count is associated with postoperative infection in patients with orthopaedic trauma who are HIV positive. Clin Orthop Relat Res. 2012;470(5):1507-12.

6. Zhao J, Cheng L, Wang H, et al. Infection and depletion of CD4+ group-1 innate lymphoid cells by HIV-1 via type-l interferon pathway. PLoS Pathog. 2018;14(1):e1006819.

7. Campoccia D, Montanaro L, Arciola CR. The significance of infection related to orthopedic devices and issues of antibiotic resistance. Biomaterials. 2006; 27(11):2331-9.
8. Winkler $\mathrm{H}$. Rationale for one stage exchange of infected hip replacement using uncemented implants and antibiotic impregnated bone graft. Int J Med Sci. 2009;6(5):247-52.

9. Gonsalves GS, Crawford FW. Dynamics of the HIV outbreak and response in Scott County, IN, USA, 2011-15: a modelling study. Lancet HIV. 2018:5(10): e569-77.

10. Andrews B, Semler MW, Muchemwa $L$, et al. Effect of an early resuscitation protocol on in-hospital mortality among adults with Sepsis and hypotension: a randomized clinical trial. JAMA. 2017;318(13):1233-40.

11. Prokuski L. Prophylactic antibiotics in orthopaedic surgery. J Am Acad Orthop Surg. 2008;16(5):283-93.

12. Henley MB, Jones RE, Wyatt RW, Hofmann A, Cohen RL. Prophylaxis with cefamandole nafate in elective orthopedic surgery. Clin Orthop Relat Res. 1986;209:249-54.

13. Noordzij M, Dekker FW, Zoccali C, Jager KJ. Sample size calculations. Nephron Clin Pract. 2011;118(4):C319-23.

14. Sebastian A, Huddleston P 3rd, Kakar S, Habermann E, Wagie A, Nassr A. Risk factors for surgical site infection after posterior cervical spine surgery: an analysis of 5,441 patients from the ACS NSQIP 2005-2012. Spine J. 2016; 16(4):504-9.

15. MCLaren AC, Lundy DW. AAOS systematic literature review: summary on the Management of Surgical Site Infections. J Am Acad Orthop Surg. 2019; 27(16):e717-717e720.

16. Berríos-Torres SI, Umscheid CA, Bratzler DW, Leas B, Stone EC, Kelz RR, et al. Centers for Disease Control and Prevention guideline for the prevention of surgical site infection, 2017. JAMA Surg. 2017;152(8):784-91.

17. Yang $Y$, Wang $L Q$, Yao BC, Guo ZG. Ubiquitin-specific protease as the underlying gene biomarker for aortic stenosis. Lipids Health Dis. 2020;19(1):115.

18. Ohno M, Shimada Y, Satoh M, Kojima Y, Sakamoto K, Hori S. Evaluation of economic burden of colonic surgical site infection at a Japanese hospital. J Hosp Infect. 2018;99(1):31-5.

19. He Y, Xiao J, Shi Z, He J, Li T. Supplementation of enteral nutritional powder decreases surgical site infection, prosthetic joint infection, and readmission after hip arthroplasty in geriatric femoral neck fracture with hypoalbuminemia. J Orthop Surg Res. 2019;14(1):292.

20. Drapeau CM, Pan A, Bellacosa C, et al. Surgical site infections in HIV-infected patients: results from an Italian prospective multicenter observational study. Infection. 2009:37(5):455-60.

21. Kigera JW, Straetemans M, Vuhaka SK, Nagel IM, Naddumba EK, Boer K. Is there an increased risk of post-operative surgical site infection after orthopaedic surgery in HIV patients? A systematic review and meta-analysis. PLoS One. 2012;7(8):e42254.

22. Liu BC, Zhang L, Su JS, Tsun A, Li B. Treatment of postoperative infectious complications in patients with human immunodeficiency virus infection. World J Emerg Med. 2014:5(2):103-6.

23. Wang $\mathrm{K}, \mathrm{Wu} \mathrm{M}, \mathrm{Xu}$ J, et al. Effects of dexmedetomidine on perioperative stress, inflammation, and immune function: systematic review and metaanalysis. Br J Anaesth. 2019:123(6):777-94.

24. Bala J, Chinnapaiyan S, Dutta RK, Unwalla H. Aptamers in HIV research diagnosis and therapy. RNA Biol. 2018;15(3):327-37.

25. Curtiss AL, Stefanovski D, Richardson DW. Surgical site infection associated with equine orthopedic internal fixation: 155 cases (2008-2016). Vet Surg. 2019:48(5):685-93 0000-0001-9350-7211 AO.

26. Zhang Y, Zhang J, Sheng H, Li H, Wang R. Acute phase reactant serum amyloid a in inflammation and other diseases. Adv Clin Chem. 2019;90:25-80.

27. van Atteveld VA, Van Ancum JM, Reijnierse EM, et al. Enythrocyte sedimentation rate and albumin as markers of inflammation are associated with measures of sarcopenia: a cross-sectional study. BMC Geriatr. 2019;19(1):233

28. Quadir AF, Britton PN. Procalcitonin and C-reactive protein as biomarkers for neonatal bacterial infection. J Paediatr Child Health. 2018;54(6):695-9.

29. Constantinescu C, Bodolea C, Pasca S, et al. Clinical Approach to the Patient in Critical State Following Immunotherapy and/or Stem Cell Transplantation: Guideline for the On-Call Physician. J Clin Med. 2019;8(6):884. https://doi. org/10.3390/jcm8060884

30. Miller RR 3rd, Lopansri BK, Burke JP, et al. Validation of a host response assay, SeptiCyte $L A B$, for discriminating Sepsis from systemic inflammatory response syndrome in the ICU. Am J Respir Crit Care Med. 2018;198(7):903-13.

\section{Publisher's Note}

Springer Nature remains neutral with regard to jurisdictional claims in published maps and institutional affiliations. 